\title{
Supporting EAL students in regional education contexts: "It creates a huge workload and often times disappointment"
}

\author{
Melissa Barnes ${ }^{(a)}$, Seham Shwayli (a) \\ and Pamalee Matthews ${ }^{(b)}$ \\ (a) Monash University \\ (b) Department of Education and Training Victoria
}

Abstract: There has been increasing attention on mainstream teacher beliefs on English as an Additional Language (EAL) students in their classrooms, particularly in regards to how these beliefs impact on teacher expectations and actions. With many teachers holding deficit beliefs towards EAL students, many have argued that professional development is one way to counter these beliefs. However, with a push for the regional settlement of migrants in Australia, there is limited understanding of mainstream teachers' beliefs about EAL students in regional contexts. Drawing on Bourdieu's concepts of habitus and field, this study investigates the beliefs of teachers and principals in two regional secondary schools in Victoria, Australia. The findings suggest that while many teachers hold common misconceptions regarding EAL students, their views regarding the inclusion of these students are generally positive and both the teachers and principals are open to additional training and support. However, the prevailing issue regarding supporting EAL students is time and/or timing-a commodity that both teachers and students do not have. This paper argues that EAL support in a regional context needs to be further interrogated, identifying a variety of approaches, such as professional development for mainstream teachers, additional EAL specialist support, and after-school programs, to better meet the needs of EAL students in regional areas.

Keywords: EAL, regional schools, secondary schooling, mainstream teachers, beliefs, Bourdieu

There has been an increasing emphasis on mainstream teachers' beliefs about English as an Additional Language (EAL) 
students (Mellom, Straubhaar, Balderas, Ariail, \& Portes, 2018; Pettit, 2011; Reeves, 2006; Sharkey, 2018; Walker, Shafer, \& Iiams, 2004), particularly given the trend to place EAL students in mainstream classrooms as opposed to providing them with specific EAL instruction (Cross, 2012; de Jong, Harper, \& Coady, 2013; Edwards, 2014; Harper \& de Jong, 2009; Sharkey, 2018; Somé-Guiébré, 2016; Torff \& Murphy, 2018). However, the majority of studies on mainstream teacher beliefs capture the views of teachers teaching in metropolitan areas which geographically tend to have more exposure to linguistic and cultural diversity (Mellom et al., 2018; Pulinx, van Avermaet, \& Agirdag, 2017). With the recent push for regional settlement in countries, such as Australia (Golebiowska, Elnasri, \& Withers, 2017; Taylor, Bell, \& Gerritsen, 2014), there is a need to explore teacher and principal beliefs regarding EAL students in schools in regional areas to ensure that incoming EAL students have access to adequate support. It is important to note that this paper did not investigate teacher and principal beliefs on Aboriginal students who speak dialects of English or Aboriginal languages, albeit its increasing importance in regional areas (see for example, Disbray, 2016).

Drawing on Bourdieu's thinking tools of habitus and field (1990a, 1990b), this study explores school teacher and principal beliefs on EAL inclusion, learning, teaching and support in a regional education context or "field". Employing an integrated mixed-method approach, with a focus on in-depth qualitative analysis, the findings suggest that while teachers hold common misconceptions regarding EAL students, they are open to professional development. However, they are overwhelmed by the time required to support EAL students-including the time to plan and modify lessons, receive professional development and to provide additional time during class. This paper argues that EAL support in regional areas needs to be further interrogated, with professional development being one of the many steps that need to be taken to address the needs of EAL students in regional areas.

\section{Mainstream teacher beliefs}

Exploring teachers' beliefs provides a lens into their practices (Mellom et al., 2018; Pettit, 2011), as beliefs "drive classroom actions and influence the teacher change process" (Richardson, 1996, p. 102). Pettit (2011) argues that beliefs influence how 
teachers think about the content they teach and the choices that they make within the classroom. Therefore, their beliefs influence not only how they approach language learning within their content area but how they provide a linguistic and culturally inclusive setting. Beliefs can also impact teacher and student interactions within the classroom, which according to Mantero and McVicker (2006), influence student achievement.

With the understanding that teacher beliefs can impact choices and actions regarding content, classroom environment, and interactions with EAL students, a number of studies have attempted to explore how in-service teachers view EAL students. For the purpose of this paper, two key aspects that influence teacher beliefs, language diversity and understanding of second language learning, are explored.

\section{Language diversity}

The literature suggests that negative attitudes, in particular, are often shaped by monolingual bias (and/or multilingual ignorance) (Mellom et al., 2018; Pulinx et al., 2017) which may be influenced by a lack of exposure to language diversity (Pettit, 2011). Pulinx et al., (2017) explored the beliefs of 775 teachers across 48 secondary schools and found that the participating schools observed the strict language policies that encouraged the exclusivity and promotion of Dutch. However, they found that monolingual policies had great traction in schools with a more evenly distributed ethnic diversity and an overall lower percentage of ethnic diversity. In other words, schools which had a higher percentage of ethnic diversity overall and consisted of large concentrations of students from one ethnic group had teachers who were more willing to address the increasing linguistic diversity of their school. Similarly, Gándara, Maxwell-Jolly, and Driscoll (2005) surveyed around 5,300 teachers in Californian schools and observed that the more EAL students that teachers had in their classrooms, the more confident they felt teaching these students. Additionally, they found that those who lived in diverse areas of California were more willing and/or prepared to meet the needs of the changing population. Therefore, exposure to linguistic diversity within the classroom and the larger community has an impact on teacher beliefs, suggesting that the more exposure to language diversity the more likely teachers will hold positive beliefs about EAL students. 
Teacher understanding of Second Language Acquisition (SLA)

In addition to exposure to language diversity, the literature suggests that teachers' understanding of second language acquisition (SLA) is also a strong predictor of teachers' beliefs. The literature suggests that teachers' lack of SLA knowledge leads to misconceptions that can promote negative views towards EAL students (Edwards, 2014; Mellom et al., 2018; Pettit, 2011; Reeves, 2006; Walker et al., 2004). For example, several studies have revealed that mainstream teachers believe that EAL learners should be fluent in English within 1-2 years within a US classroom (Reeves, 2006; Walker et al., 2004), when most research suggests that it typically takes anywhere from 4 to 7 years to develop English language proficiency (Creagh, Kettle, Alford, Comber, \& Shield, 2019; Thomas \& Collier, 2002; Thompson, 2017). This tension between their beliefs regarding how long it should take for a student to develop English language proficiency, particularly when they assume that this should take only a few years, can lead to unrealistic expectations that are frustratingly unrealised, resulting in negative views regarding EAL students' ability and/or willingness to engage with the content. In addition to understanding how long it should take to learn English, a number of studies found that teachers did not always recognise the role of the students' first language in the development of English and some considered their first language a hinderance to English language learning (Edwards, 2014; Mellom et al., 2018; Reeves, 2006; Walker et al., 2004). For example, in Mellom et al.'s (2018) randomised control trial, consisting of $1473^{\text {rd }}$ and $5^{\text {th }}$ grade teachers who were teaching across 47 high-poverty schools, they found that many of the teachers had negative views about students' first (or home) language. Their study found that many of the teacher participants criticised students using a language other than English both at school and at home. One participant negatively lamented that even though the parents were born in the US, they were still not speaking English at home. Many of these participants associated students' use of their first language with crime or poverty and explicitly asked students not to speak their first language at school.

Combined with teachers' misconceptions and their limited exposure and/or understanding of SLA, a number of studies report that mainstream teachers have found working with EAL students extremely time-consuming, and it is simply time, they argue, they do not have (Edwards, 2014; Hansen-Thomas, Grosso 
Richins, Kakkar, \& Okeyo, 2016; Reeves, 2006; Walker et al., 2004). This is because time is needed to grasp additional SLA knowledge and skills to effectively plan lessons (Edwards, 2014; Hansen-Thomas et al., 2016), to assess and understand students' English language proficiency levels in order to modify current content (Reeves, 2006), and to pursue professional development in SLA (Hansen-Thomas et al., 2016).

To counter negative beliefs and/or misconceptions about SLA, a number of studies argue that professional development is key (Mellom et al., 2018; Sharkey, 2018). Mellom et al. (2018) argue that given the strong role that cultural assumptions and prejudices play in teachers' beliefs, and therefore their actions in the classroom, teachers require training in culturally responsive pedagogies (see, for example, Ladson-Billings, 1995; 2014). Likewise, Edwards (2014), in her work with mainstream secondary teachers in New Zealand, argues that teachers lack the knowledge of how to effectively support EAL learners. Therefore, teachers need training in how to plan, use existing resources and acquire language focused strategies to implement within their classrooms.

In light of this literature, this paper explores principal and teacher beliefs on supporting EAL students in regional areas.

\section{Rural contexts: Challenges and opportunities}

While there has been a handful of research studies exploring mainstream teacher beliefs in regional areas (Gándara et al., 2005; Hansen-Thomas et al., 2016; Walker et al., 2004), there has been a dearth of research focusing on teacher beliefs of EAL students in Australian regional and rural schooling contexts. In light of more recent immigration policies, the numbers of EAL learners in regional schools in Australian schools are increasing and set to rise even further (Mooney \& Hickey, 2016). One reason for this increase is due to a push by the Federal Government to settle newly arrived refugees and migrants into regional areas as a means to address population decline in regional areas and counter overpopulation in metropolitan areas (Golebiowska et al., 2018; Taylor et al., 2014). Recently, there have been political discussions regarding regional migration schemes and an impetus for "bonding" new migrants to regional areas (Acharya, 2018; Baxendale, 2018; Crowe, 2018; Kainth, 2018). However, regional areas, in general, struggle to attract and retain teaching staff in comparison to metropolitan areas (Cuervo \& Acquaro, 2018; Halsey, 2018: McKenzie, Weldon, Rowley, Murphy, \& McMillan, 
2014), and this makes finding teachers, among the limited pool, who have background knowledge and training in SLA and a multilingual view of learning problematic (Gándara et al., 2005; Hansen-Thomas et al., 2016; Walker et al., 2004). Additionally, Hansen-Thomas et al. (2016) investigated the professional development needs of teachers who taught EAL students in regional areas in the USA, and found that regional schools often lack access to professional development opportunities due to a lack of financial and material sources.

While finding teachers with training in SLA or having access to long-term, sustainable professional development (Sharkey, 2018) is a challenge for regional education contexts, these areas are still ripe for opportunities to develop culturally responsive communities. Several studies have reported that regional areas can provide a strong sense of community for migrants and refugees, particularly when there is a concentration of one ethnic or cultural group, allowing them to develop a strong sense of wellbeing (Joyce \& Liamputtong, 2017; Townsend, Pascal, \& Delves, 2012). However, as Mellom et al. (2018) argue, there is a need to understand and address cultural assumptions and stereotypes to be able to provide ways forward in developing teachers who are equipped with culturally responsive pedagogies.

\section{Theoretical framing: Bourdieu's habitus and field}

Bourdieu's thinking tools allow for a thorough examination of the social relations that exist within a particular education context (or field) and how individuals are shaped by and shape these fields. This study explores how teacher and principal beliefs and dispositions about EAL students are shaped by and shape the field of regional secondary schooling. Teachers' habitus, or their "acquired, socially constituted dispositions" (Bourdieu, 1990a, p. 13) are not only shaped by their past experiences but are also shaped through the negotiation of current social norms. Bourdieu (1990b) contends that the habitus reproduces "the social conditions of our own production" (p. 87) and while this can result in individual actions, these actions are often confined to those which are socially acceptable within a particular field. Therefore, habitus are reproduced within the social norms of a regional educational field (Bourdieu, 1990b). In other words, teachers are often socialised to think and act in similar ways to those around them and then (re)produce these same norms. Teachers and principals reflect the social norms of a specific social context (Pettit, 2011; 
Walker et al., 2004), which can be problematic if the context proffers a monolingual approach to learning due to a lack of language diversity as is sometimes the case in a rural setting. Therefore, teachers and principals must actively negotiate these norms in light of increasing linguistic and cultural diversity within their schools.

\section{Methods}

Context

Set within a regional area in the Australian state of Victoria, two secondary schools were invited to participate in this study as they were part of a state-funded English as an Additional Language (EAL) Cluster Program. The EAL Cluster Program is available for regional and/or rural schools and enables these schools to combine their state education entitlements to employ an EAL teaching specialist (Department of Education and Training [DET], 2019) to provide teachers advice and guidance on teaching and supporting EAL students in their classrooms. This results in one EAL teaching specialist working across a number of schools (e.g. in the case of this area, one EAL specialist was assigned to nine different schools). Their role is to support teachers as they do not have the capacity to teach EAL students directly.

With the help of the EAL Cluster Teacher within this region, two schools volunteered to be part of this study. Both participating secondary schools have Index of Community Socio-Educational Advantage values lower than the average Australian school (ACARA, 2019), which classifies this region as having a lower socio-economic status than other areas within Australia. The school principals were first invited to participate in an interview and then were asked to pass on an online survey to their teachers.

\section{Research design}

This study employs an integrative mixed methods (IMM) approach. The qualitative aspect of this study is the dominant feature as the study aimed to explore principals' and teachers' beliefs within the field of regional education. Quantitative data were also collected via the survey. To measure teachers' attitudinal beliefs, 16 Likert-scale questions were employed, but keeping true to its qualitative focus, five open-ended questions enabled teachers to voice or elaborate on their attitudinal scale ratings. These scales were helpful in establishing individual dispositions or 
habitus, in addition to finding patterns of collective habitus among teachers within a regional field. The 16 Likert-scale items were adapted from Reeves' survey (2006) measuring secondary teacher's attitudes towards the inclusion of EAL students in mainstream classrooms in the US. These questions were included as they were piloted and validated for use in Reeves' broader study and have subsequently been used as a basis for other studies exploring mainstream teacher beliefs.

For a quantitative study to be valid and reliable, the sample size needs to be large enough to demonstrate that the sample is representative of the larger population. With only 25 teachers responding to the survey, out of the 150 full-time teachers across both schools, it is problematic to argue that statistically their beliefs represent the views held by the field (e.g., a regional education context). However, this study, which draws from a small community and draws upon its qualitative bend, provides enough quantitative data saturation that a smaller and more manageable sample size is still able to provide meaningful findings due to its focus on the qualitative aspects of the survey and interviews (Castro, Kellison, Boyd, \& Kopak, 2010).

Principals from both schools were interviewed and recorded individually (each interview lasting from 45 to 60 minutes), which added an alternative, educative, yet authoritative perspective, unpacking some of the social, political and power structures of these schools. This provided an important backdrop to understanding the field, in which collective and individual habitus interacts, and provided a base to explore individual teachers' beliefs as depicted within the survey.

Tasked with exploring principals' and teachers' beliefs and experiences in a regional education context, this study aimed to answer the following question: What are the beliefs of school leaders and mainstream teachers towards EAL learning, teaching, support and inclusion?

\section{Data analysis}

Qualtrics, an anonymous survey platform, was employed for this study as both a tool for data collection and for data analysis. Descriptive statistics (e.g., mean, medium and percentage values) of the 7-point Likert-scale items were generated. Qualitative analysis consisted of two stages; The transcriptions of the individual interviews as well as the responses to open-ended 
questions in the teacher survey were analysed vertically and then horizontally (Merriam \& Tisdell, 2016). The individual interviews and the open-ended responses were analysed separately, allowing for themes to emerge and generate initial codes (vertical analysis). Once all codes were identified, these codes were linked to the theoretical underpinnings of the study to ensure that theoretical connections were made but also to establish meaningful findings that went beyond this framework. Finally, a second analysis was conducted to compare the emerging common themes and patterns from all data sources to provide a coherent unified voice from the social field (horizontal analysis).

Below, we outline the key findings that emerged from the interviews and surveys in regards to 1) common misconceptions in light of classroom realities and 2) the need for more than just professional development.

\section{Findings}

\section{Common misconceptions in the face of classroom realities}

Similar to other studies (Reeves, 2006; Walker et al., 2004), 20 out of 25 of the participating teachers held the common misconception that EAL students should be able to "acquire English" within two years of being in the Australian school system. These same 20 teachers claimed that EAL students should not be included in general education classes until they attain a minimum standard of English language proficiency. This then, creates tensions within the classroom as teachers harbour feelings that suggest students, with limited English proficiency, should not be placed in their mainstream classrooms. One teacher commented:

In my experience, EAL students that I have taught have been extremely unprepared for the level of the courses that I teach. They have had little to no specific language support or cultural support and it has been up to me alone to help them. This is often too little as they are so behind in their skills that often there are huge gaps in understanding.

This teacher is arguing that EAL students, or at least the ones that he/she has had, should not be in his/her classroom until they have the required English language proficiency as they currently do not have the skills to succeed. This is not a rejection of the student but the rejection of the mainstreaming of EAL students. However, this is problematic for students in regional secondary schools in Australia because there are not enough EAL 
students to offer intensive language programs so they have no other place to go than to mainstream classrooms. Additionally, given that 22 of the 25 teachers agreed with the statement that they "welcome the inclusion of EAL students" in their classrooms, this suggests that they do not always feel the students should be in a mainstream classroom until they have a minimum standard of English proficiency.

The findings also suggest that while teachers welcome the inclusion of these students, supporting these students, particularly linguistically and culturally, adds to their workload and requires the availability of an intensive language program or an EAL specialist:

We often are teaching students who have arrived recently in Australia who have had no intensive language support. It's unacceptable. To the student, the family and the teacher. It creates a huge workload and often times disappointment.

We desperately need an aide with EAL skills like we used to have. They were helpful to the students as they helped to build skills and confidence and they were enormously helpful to staff.

These comments affirm the teacher beliefs expressed previously that students require intensive language programs before entering a mainstream classroom. It is perceived that having EAL students in one's classroom creates an increased workload yet limited hope of successfully supporting these students.

\section{A lack of time to support students and receive specialised training}

The time needed to support EAL students in their classroom is a key consideration for teachers. Twenty of the 25 teachers agreed with the statement: "Mainstream teachers do not have enough time to deal with the needs of EAL students." With seven strongly agreeing, ten agreeing and three somewhat agreeing, time is considered a key determinant in their ability to support their EAL students. When asked in the survey what the greatest challenge(s) were in relation to the inclusion of EAL students in their classrooms, time emerged once again:

Finding time to plan effectively for the EAL student and then finding enough class time to work with them. 
Lack of time for one on one teacher and student direction.

Not trained and no time for training,

The teachers' comments suggest that time to plan and support EAL students in class is lacking. It is also suggested that they lack the time to receive adequate training to meet these students' needs.

Twenty of the 25 teachers indicated that they were interested in receiving more training and professional development to work with EAL students. Three teachers were not interested in receiving any further training, while two were undecided. To meet the needs of their EAL students, the majority of teacher participants felt that the coursework needed to be simplified $(n=19)$ and that students should be allowed more time to complete their work $(\mathrm{n}=20)$.

While the participating regional schools were part of the EAL Cluster program, which aimed to support mainstream teachers, both principals (pseudonyms used) felt that they needed more:

The Cluster Program's great and it really does help, but the bottom line is we need to be able to sustain something within our school and our teachers need to be trained to support EAL students (Sally, interview).

We all have small number of EAL students therefore we pool resources and use the pooled resources to provide support. I don't think that model is necessarily a bad one, the underlying problem with it is that the amount of resources that come from that to allow pooling, I think needs to be greater (Adam, interview).

Principals and teachers want more resources, funding, support and time. While professional development is a start to addressing EAL student needs, it is suggested that how EAL students are supported in regional areas needs to be supported by timing, support services and funding:

We're just not capable in terms of teacher knowledge and funding and timing, resources to give them the level of support that would require and sometimes it's not within the timeframe that we have to work with those students for that to be able to happen either. (Sally, interview) 
It is not that EAL students cannot achieve great things, it is a mismatch between skills, timing, aspiration, support services, etc.

Both Sally and the teacher above are referring to upper secondary school as students arrive with limited language proficiency and gaps in knowledge and do not have the time to develop both language and content knowledge to do well on their final exams.

\section{Discussion: When time and timing matters}

The teachers' reported concern of having insufficient time to adequately address EAL student needs, aligns with the findings of a number of other studies who have reported that mainstream teachers find working with EAL students very time-consuming (Edwards, 2014; Hansen-Thomas et al., 2016; Reeves, 2006; Walker et al., 2004). Many of the teachers, in this study, reported in the survey that to address student needs they needed to modify coursework and/or give additional time to students, which creates the need for both planning time (Edwards, 2014; Hansen-Thomas et al., 2016; Reeves, 2006) and additional class time within an already overcrowded curriculum (Caldwell, 2015). In their longitudinal study exploring secondary school completion among refugees in Melbourne, Australia, Correa-Velez, Gifford, McMichael, and Sampson (2017) found the age on arrival creates a significant barrier to secondary school completion. They found that those arriving at an older age struggled to complete secondary school because they "are entering secondary school at higher year levels with significant educational expectations and workload" (Correa-Velez et al., 2017, p. 799). This suggests that EAL students entering at secondary school are also short of time to develop both language and content skills under the expectations and workload of secondary schooling. They require additional class time to meet expectations, however, there is limited time in class and limited support inside and outside of the classroom for them to successfully complete the class work and exams required for completion.

In addition to the perceived lack of time available for teachers to address student needs and EAL students to be successful in secondary school contexts, teacher and principal beliefs, or habitus, is being shaped and is shaping the field of regional education-a context which is characterised by limited linguistic and cultural diversity. This study reveals the dominant 
belief among the participating teachers that they require additional support from specialist EAL teachers as they are unable to adequately meet the needs of these students on their own. While there is a paradigm shift towards providing support to EAL students in mainstream classes in metropolitan areas (de Jong et al., 2013; Edwards, 2014; Sharkey, 2018), many regional teachers lack the opportunities for exposure to language and cultural diversity (Gándara et al., 2005; Pettit, 2011). Therefore, professional development may be a way forward to disrupt and address current misconceptions. For example, training in SLA can help teachers understand that it takes 4 to 7 years for students to develop English language proficiency (Creagh et al., 2019; Thomas \& Collier, 2002; Thompson, 2017) rather than their reported belief that English language proficiency can be developed within two years of being in an Australian school. Also, professional development can help equip these teachers with strategies to support their EAL students within their classroom, with or without the additional support of a specialist EAL teacher.

With this, professional development programs not only need to be culturally responsive (Mellom et al., 2018) but would need to be regionally responsive by addressing misconceptions held among teachers and proactively finding ways to build capacity within schools through resources that are already available. Furthermore, while professional development can be a valuable tool for addressing cultural assumptions and prejudices that shape teacher habitus (Mellom et al., 2018), it requires a whole-school approach and new ways of thinking about what support for EAL students looks like, particularly in a regional area.

\section{Concluding remarks}

This small-scale study provides a glimpse into teacher and principal beliefs on EAL students in regional areas. While the data is limited by a small number of participants and schools, it supports what previous literature suggests about mainstream teacher beliefs but highlights how this is further shaped by a regional education field. While we can disrupt teacher and principal habitus through professional development that addresses misconceptions, there is more required to ensure that the needs of EAL students are met. With increasing numbers of EAL students set to relocate to regional areas and teacher beliefs suggesting that they do not have the time to address EAL student 
needs, there needs to be a fresh approach to what constitutes EAL support, and more specifically, what this looks like in regional areas inside and outside the mainstream classroom. More specifically, this may include: support from EAL specialists, mainstream teachers who have had EAL training, after-school community language programs, and a new secondary school structure for EAL students that includes intensive language programs as well as a modified schedule to allow them to complete their secondary schooling over several years. If regional areas want to attract more people into these areas, regional schools must be the centre of "opportunity" and excellence that migrants and refugees seek. Therefore, professional development may be one step towards addressing EAL support in regional areas but is just the first of many.

\section{References}

Acharya, M. (9 August, 2018). Australia to trial new ways for settling migrants in regional areas. SBS. Retrieved from https://www.sbs.com.au/yourlanguage/hindi/en/ article/2018/08/09/new-ways-being-trialled-settle-migrantsregional-australia

Australian Curriculum and Reporting Authority (ACARA). (2019). My School. Retrieved from https://www.myschool. edu.au

Baxendale, R. (2018, October 9). New incentives will be offered to migrants who settle outside of cities. The Australian. Retrieved from https://www.theaustralian.com.au/

Bourdieu, P. (1990a). In other words: Essays towards a reflexive sociology. Cambridge: Polity Press.

Bourdieu, P. (1990b). The logic of practice. Cambridge: Polity Press.

Caldwell, B. (2015). Feeling overwhelmed?: It is time for serious innovation. Australian Educational Leader, 37(1), 14-17.

Castro, F., Kellison, J., Boyd, S., \& Kopak, A. (2010). A methodology for conducting integrative mixed methods research and data analyses. Journal of Mixed Methods Research, 20(4), 342-360. doi:10.1177/1558689810382916

Correa-Velez, I., Gifford, S., McMichael, C., \& Sampson, R. (2017). Predictors of secondary completion among refugee youth 8 to 9 years after resettlement in Melbourne, Australia. International Migration $\mathcal{E}$ Integration, 18(1), 791-805. doi: $10.1007 / \mathrm{s} 12134-016-0503-\mathrm{z}$ 
Creagh, S., Kettle, M., Alford, J., Comber, B., \& Shield, P. (2019). How long does it take to achieve academically in a second language? Comparing the trajectories of EAL students and frist language peers in Queensland Schools. Australian Journal of Language and Literacy, 42(3), 145-155. Retreived from https://eprints.qut.edu.au/131787/

Cross, R. (2012). Reclaiming the territory: Understanding the specialist knowledge of ESL education for literacy, curriculum, and multilingual learners. TESOL in Context, 22(1), 4-17. Retrieved from https://search.informit.com.au/

Crowe, D. (2018, October 9). Demand for detail as coalition repeats call for regional migration. Sydney Morning Herald. Retrieved from https://www.smh.com.au/politics/federal/ demand-for-detail-as-coalition-repeats-call-for-regionalmigration-20181009-p508j9.html

Cuervo, H., \& Acquaro, D. (2018). Exploring metropolitan university pre-service teacher motivations and barriers to teaching in rural schools. Asia-Pacific Journal of Teacher Education, 46(4), 384-398, doi:10.1080/135986 6X.2018.1438586

de Jong, E. J., Harper, C. A., \& Coady, M. R. (2013). Enhanced knowledge and skills for elementary mainstream teachers of English language learners. Theory into Practice, 52, 89-97. doi:10.1080/00405841.2013.770326

Department of Education and Training (2019). EAL Funding Program. Retrieved from https://www.education.vic.gov. $\mathrm{au} / \mathrm{school} /$ teachers/management/finance/Pages/ srpref026.aspx

Disbray, S. (2016). Spaces for learning: policy and practice for indigenous languages in a remote context. Language and Education, 30(4), 317-336. doi:10.1080/09500782.2015.1114 629

Edwards, S. (2014). Supporting English language learners: New Zealand secondary mainstream teachers' knowledge and use of recommended teaching resources and strategies. New Zealand Journal of Educational Studies, 49(1), 43-58. Retrieved from http://researcharchive.wintec.ac.nz/3160/

Gándara, P., \& Maxwell-Jolly, J., \& Driscoll, A. (2005). Listening to teachers of English language learners: A survey of California teachers' challenges, experiences, and professional 
development needs. Policy Analysis for California Education, PACE. Retrieved from https://escholarship.org/uc/ item/6430628z

Golebiowska, K., Elnasri, A. B., \& Withers, G. (2017). Responding to negative public attitudes towards immigration through analysis and policy: Regional and unemployment dimensions. In N. Klocker, \& O. Dun (Eds.), Population, Migration and Settlement in Australia and the Asia-Pacific: In Memory of Graeme Hugo (pp. 63-82). Routledge Taylor \& Francis Group.

Halsey, J. (2018). Independent review into regional, rural, and remote education. Retrieved from https://www.education.gov.au/ independent-review-regional-rural-and-remote-education

Hansen-Thomas, H., Richins, L., Kakkar, K., \& Okeyo, C. (2016). I do not feel I am properly trained to help them! Rural teachers' perceptions of challenges and needs with Englishlanguage learners. Professional Development in Education, 42(2), 308-324. doi:10.1080/19415257.2014.973528

Harper, C., \& de Jong, E. (2009). English language teacher expertise: The elephant in the room. Language and Education, 23(2), 137-151. doi:10.1080/09500780802152788

Joyce, L., \& Liamputtong, P. (2017). Acculturation stress and social support for young refugees in regional areas. Children and Youth Services Review, 77(1), 18-26. doi:http://dx.doi. org/10.1016/j.childyouth.2017.03.016

Kainth, S. (2018, October 15). New plan to settle migrants in regional areas. SBS. Retrieved from https://www.sbs.com. $\mathrm{au}$ /yourlanguage/punjabi/en/article/2018/08/29/newmigrants-may-have-live-regional-australia-5-years

Ladson-Billings, G. (1995). Toward a theory of culturally relevant pedagogy. American Educational Research Journal, 32(3), 465491. doi:10.3102/00028312032003465

Ladson-Billings, G. (2014). Culturally relevant pedagogy 2.0: A.K.A. The remix. Harvard Educational Review, 84(1), 74-84. doi:10.17763/haer.84.1.p2rj131485484751

Mantero, M., \& McVicker, P. (2006). The impact of experience and coursework: Perceptions of second language learners in the mainstream classroom. Radical Pedagogy, 8(1), 1-23. Retrieved from http://radicalpedagogy.icaap.org/content/issue8_1/ mantero.html 
McKenzie, P., Weldon, P., Rowley, G., Murphy, M., \& McMillan, J. (2014). Staff in Australia's schools 2013: Main report on the survey. Retrieved from https://research.acer.edu.au/tll_ misc/20/

Mellom, P., Straubhaar, R., Balderas, C., Ariail, M., \& Portes, P. (2018). "They come with nothing:" How professional development in a culturally responsive pedagogy shapes teacher attitudes towards Latino/a English language learners. Teaching and Teacher Education, 71(1), 91-107. doi:10.1016/j. tate.2017.12.013

Merriam, S., \& Tisdell, E. (2016). Qualitative research: A guide to design and implementation. San Francisco, CA: John Wiley and Sons.

Mooney, A., \& Hickey, C. (2016). "Knowing the rules of the game": Rural sporting biographies and their influence on physical education pedagogy. In A. K. Schulte \& B. WalkerGibbs (Eds.), Self-studies in rural teacher education (pp.123138). Berlin, Germany: Springer. doi:10.1007/978-3-319$17488-47$

Pettit, S. (2011). Teachers' beliefs about English language learners in the mainstream classroom: A review of the literature. International Multilingual Research Journal, 5(2), 123-147. doi :10.1080/19313152.2011.594357

Pulinx, R., Avermaet, P., \& Agirdag, O. (2017). Silencing linguistic diversity: The extent, the determinants and consequences of the monolingual beliefs of Flemish teachers. International Journal of Bilingual Education and Bilingualism, 20(5), 542556, doi:10.1080/13670050.2015.1102860

Reeves, J. (2006). Secondary teacher attitudes toward including English-language learners in mainstream classrooms. The Journal of Educational Research, 99(3), 131-143. doi:10.3200/ JOER.99.3.131-143

Richardson, V. (1996). The role of attitudes and beliefs in learning to teach. In J. Sikula, T. J. Buttery, \& E. Guyton (Eds.), Handbook of research on teacher education (pp. 102-119). New York: Macmillan.

Sharkey, J. (2018). The promising potential role of intercultural citizenship in preparing mainstream teachers for im/ migrant populations. Language Teaching Research, 22(5), 570-589. doi:10.1177/1362168817718577 
Somé-Guiébré, E. (2016). Mainstreaming English language learners: Does it promote or hinder literacy development? English Language Teaching, 9(1), 33-40. doi:10.5539/elt. v9n1p33

Taylor, A., Bell, L., \& Gerritsen, R. (2014). Benefits of skilled migration programs for regional Australia. Journal of Economic and Social Policy, 16(1), 1-23. Retrieved from https://epubs.scu.edu.au/jesp/vol16/iss1/3/

Thomas, W., \& Collier, V. (2002). Reforming education policies for English learners means better schools for all. The State Education Standard, 3(1), 30-36. (The journal of the National Association of State Boards of Education, Alexandria, VA.) Retrieved from https://www.thomasandcollier.com/articles

Thompson, K. (2015). English learners' time to reclassification: An analysis. Educational Policy, 31(3), 330-363. doi:10.1177/0895904815598394

Torff, B., \& Murphy, A. (2018). Placement of former English language learners in middle schools: General education or dual language? International Journal of Bilingual Education and Bilingualism. doi:10.1080/13670050.2018.1494697

Townsend, R., Pascal, J., \& Delves, M. (2014). South East Asian migrant experiences in regional Victoria. Journal of Sociology, 50(4), 601-615. Retrieved from https://us.sagepub.com/ en-us/nam/journal/journal-sociology

Walker, A., Shafer, J., \& Iiams, M. (2004). 'Not in my classroom: Teacher attitudes towards English language learners in the mainstream classroom. NABE Journal of Research and Practice, 2(1), 130-160. Retrieved from https://www2.nau.edu/ nabej-p/ojs/index.php/njrp/index 
Dr Melissa Barnes is a lecturer in the Faculty of Education at Monash University working within the fields of teacher education, assessment, policy and TESOL. She teaches and leads research initiatives that focus on policy construction, interpretation and enactment, with a focus on how policies impact and shape teaching and learning. She has published in journals such as Critical Studies in Education, Discourse: Studies in the Cultural Politics of Education and English for Academic Purposes, among others.

melissa.barnes@monash.edu

Dr Seham Shwayli recently finished her PhD at Monash University in 2015. She received her Master of Education in TESOL and Linguistics from Monash in 2010 and her Bachelor in Arts / English Education from Basra University, Iraq in 1996. Her PhD, "What Kind of Inclusion: Iraqi Muslim Women's Experiences in Australia" focuses on social inclusion and challenges facing Muslim women and their families in Multicultural Australia.

seham.shwayli@monash.edu

Pamalee Matthews has been teaching for more than 30 years and has always been interested in furthering her studies and taking on new positions and roles. Seven years ago, she became involved in teaching English as an Additional Language. It has been the highlight of her career, particularly teaching English to refugees and new arrivals. Pamalee is passionate about improving the educational outcomes for EAL students in regional areas.

matthews.pamalee.p@edumail.vic.gov.au 
